\title{
Increasing Rate of Diffusion of Innovation in Supply Chain: Targeting the Early Adopters in UK Supply Chain
}

\author{
S.Y. Lee ${ }^{1}$, M.K. Lim², D. Food ${ }^{3}$ and J. Hu \\ ${ }^{1}$ Coventry University, Coventry CV1 5FB, UK \\ ${ }^{2}$ Chongqing University, Chongqing 400044, China \\ ${ }^{3}$ University of Warwick, Coventry CV4 7AL, UK \\ siryee88@gmail.com
}

\begin{abstract}
Innovations (technology and software) had revolutionized the modern supply chain and bring numerous benefits. Nevertheless, not all party in a supply chain is ready to embrace and adopt the innovations when they are first released due to the substantial risk and uncertainty. Early adopters however are bold enough to take the risk in trying an innovation and later lead the late adopters in using the said innovation, which also act as a motivator in helping to spread and diffuse that innovation. This research aimed to look for characteristics of early adopters in UK supply chain at the firm level, specifically within purchasing of software innovation. It is discovered that the early adopters in UK supply chain fit the description that was put forward by various researchers stating that early adopters are quick, bold and take the risk in purchasing a new software that is just released to the market even if they are expensive. They will advise other company to buy a good software. They however do not exhibit clear traits in their company profile, in terms of size, age and type of industry. The profile of the purchasing manager(s) in the firm also fail to exhibit distinct characteristics in term of gender and age. The media habit and software usage, as well as methods to gather information about new software, however reveal some positive results. They are willing to join any group in social media and they use most social media apart from LinkedIn.
\end{abstract}

Keywords: Early adopter, Supply chain, Diffusion of innovations.

\section{Introduction}

\subsection{Innovations and supply chain}

As recently as 1990s, supply chain operations were highly disorganised and inefficient where average time for a company to process and deliver merchandise from warehouse inventory to a customer ranged from 15 to 30 days, due to inefficiencies in orders preparation, processing, picking and delivery. Thankfully, impregnations of innovations had successfully introduced massive changes to the incompetent 
operations, for example, commercialisation of technology such as computer, internet and information transmission system as well as development of Software such as Enterprise Resources Planning software (ERP) had effectively minimised the problems faced in supply chain. Apparently, innovations could revolutionise the supply chain and make supply chain to be more efficient [1].

\subsection{Diffusion of innovations and role of early adopters}

Despite of the numerous benefits innovations can offer, research shown that not all party in a supply chain is ready to embrace and adopt the innovations when they are first released due to the substantial risks and uncertainties [2]. Analysis of several hundred of major innovations over past two centuries shows that the time an innovation takes to be mature (also known as rate of diffusion) for different innovations are different, with a typical span between ten to fifty years between innovation and successful diffusion [3].

This delayed in diffusion rate is because as high as $84 \%$ of people in the population possess high degree of scepticism and a small risk appetite, causes them to not adopt an innovation when it is first introduced to them [2]. Rogers [2] in his model of Diffusion of Innovations (DOI), shows that innovation can only diffuse after a critical mass of adopters had existed, where the proportion of firms already using an innovation would increase the rate of diffusion by exerting competitive pressures among late adopters.

Drawing from the literature, it is hypothesised that identifying the early adopter helps in attaining critical mass quicker and catalyse diffusion of innovation. Nevertheless, there is a gap falling short in studying the characteristics of early adopters in supply chain to help in accretion of critical mass of adopters. Existing research mostly focus on general or macro-level characteristics of early adopters, where its application on micro-level supply chain company, especially focusing on purchasing of software innovation, is scarcely studied. This research thus aimed at closing the gap by looking for early adopters at the firm level, in SC specifically in the UK, within purchasing of software innovation. Subsequently extract their characteristics from various dimensions, such as company profile, profile of purchasing manager(s) in the company, company's media habit, and methods of gathering information about new software. This can contribute by ensuring fast diffusion of innovation in supply chain which ultimately benefit the entire supply chain in the UK.

\subsection{Characteristics of early adopter at the firm level}

Researchers that studied on characteristics of early adopters shows that they possess distinctive attitude towards innovations. At the firm level, early adopters are found to be higher in rate of purchasing an innovation compared to late adopters (i.e.: they adopt higher number of innovations from an available pool of innovations within a given period) [4]. They are bold and take the risk in purchasing a new software that is just released to the market (i.e. having larger risk appetite or risk tolerance) that allows them to adopt technologies that may ultimately fail. The financial resources are one of the 
factors that increase their risk tolerance by helping them to absorb the cost in case of failures. They are richer and insensitive to price of the innovations, which causes them to use the best quality innovations regardless of the price, as the cost of failures can be easily absorbed. They are also better educated, more literate, have higher social status and more upward social mobility, making them have tendency to advise others, as they enjoy being respected by his/her peers and enjoy having a reputation for successful and discrete use of innovative ideas [2].

In the context of organisational/company, size was found to be the common characteristics possessed by early adopters' company but empirical evidence regarding the impact of size shows mixed results. Also, due to imbalance in nature of income distribution, early adopter is richer and able to afford an innovation, where more consumers (late adopters) can only afford it when the price of an innovation falls. They are also generally found to have founded for a long time compared to the late adopters' firm (i.e.: more senior and consequently more experienced and possesses higher degree of opinion leadership, social status, financial liquidity and connection to knowledge and financial providers). Besides, different type industries (primary/ secondary/ tertiary/ quaternary) were found to positively correlate with level of innovations adoption [5].

Other than that, gender and age of a purchasing manager were also found to correlate with the innovations adoption and its diffusion, with gender being positively correlated with diffusion rate and vice versa for age. They also tend to have higher degree of centralisation (i.e.: decisive power concentrate on few individuals). Further, they are socially active and inclines towards creating reviews around product they like or dislike and tend to utilise technology to aid their daily operation more than a late adopter. Whether or not these observations can be observed in UK supply chain, especially within the purchasing of innovations, is the primary focus of this research [6].

\section{$2 \quad$ Method}

\subsection{Sampling and data collection}

Data for the study were obtained from online survey of $500 \mathrm{SC}$ executives from micro companies and SMEs in the UK. The SC executives were invited to participate in this study using LinkedIn social media. A total of 60 valid responses were received (a 12\% response rate). The low response rate might be attributed to the length of questionnaire and the fact that no follow up was used to improve the response rate.

\subsection{Profile of responding companies}

The responding firms present in all industry sectors [11.1\% in Primary (raw material extraction), $46 \%$ in secondary (manufacturing), $28.6 \%$ in tertiary (service), and $9.5 \%$ in quaternary (high tech)]. The distribution of companies in terms of their age (or years of establishment) is almost equal (57.1\% founded less than 50 years and $42.9 \%$ founded at least 50 years). The respondents' seniority ranged from lower management, manager and senior management $(28 \%, 58 \%$, and $14 \%$ respectively). As our study used a selfadministered questionnaire, this mix is very important to provide responses that is free 
from cognitive biases, as the respondents from senior management position would be responding to survey that present themselves in a favourable manner.

\subsection{Measurement of Early adopters}

The key sampling element in the study was the early adopter. This group of adopters was identified through one closed-question on the questionnaire, where respondents are asked to select their level of agreement using 5-point scale ( $1=$ "strongly disagree" and $5=$ "strongly agree") towards the statement: "my company consider itself as an Early Adopter". Of the 60 respondents, 3 respondents ( 5 percent) identified themselves as early adopters who "strongly agree" with the statement. It is these 3 respondents who were classified in this study as "Early adopters" and whose responses were contrasted with the other 57 respondents (95 percent) to examine possible differences in several dimensions. This 1:19 ratio of respondents of Early adopters compared to the late adopters differ from the general distribution proposed by Rogers [2] in model of DOI, which is $1: 39$. However, the distribution discovered from this study compared very favourably with recent findings reported by Cecere [7].

\section{Results and discussion}

For each of the dimension, differences in responses between early adopters and late adopters (remainder of the samples) were investigated. Since both independent and dependent variables were treated as nominally scaled variables, bivariate chi-square analysis was used to investigate frequency differences in the responses. Specifically, comparisons were made of the number of early adopters and late adopters in various dimensions. The attitude towards innovation for both early adopters and late adopters were explored. Among five attitudes investigated, four exhibit significant chi-square scores $(\mathrm{p} \leq 0.05)$ which similar to the theory that was put forward by Rogers [2]. Early adopters in UK supply chain tend to advise other company to buy software $\left(\mathrm{X}^{2}=38\right)$, bold and take the risk in purchasing a new software that is just released $\left(X^{2}=24.4\right)$, buy a new software more quickly than others when it is released $\left(X^{2}=5.12\right)$, and using the best quality software even if it is expensive $\left(X^{2}=5.12\right)$. However. difference in price sensitivity between early adopters and late adopters could not be observed in adopters in the UK supply chain.

Table 1. Characteristics of Early adopters vs. late adopters.

\begin{tabular}{lccc}
\hline Category & $\begin{array}{c}\text { Early adopters } \\
(\mathrm{n}=3) \\
(\%)\end{array}$ & $\begin{array}{c}\text { Remainder of } \\
\text { the sample } \\
(\mathrm{n}=57)\end{array}$ & $\mathrm{X}^{2}$ \\
& & $(\%)$ & \\
\hline More than 100 employees & 100 & 85 & 0.56 \\
Founded more than 50 years old & 33 & 43 & 0.16 \\
Generate more than £700k turnover & 100 & 85 & 0.523 \\
Involved internationally & 100 & 87 & 0.434
\end{tabular}




\begin{tabular}{|c|c|c|c|}
\hline Listed in the list of fortune 500 & 67 & 33 & 1.45 \\
\hline Involved in primary industry & 67 & 46 & 0.293 \\
\hline Involved in secondary industry & 33 & 29 & 0.468 \\
\hline Involved in tertiary industry & 0 & 9 & 0.967 \\
\hline Involved in quaternary industry & 0 & 10 & 0.38 \\
\hline Male only manager, which is: & 100 & 84 & 0.193 \\
\hline A male & 100 & 46 & 1.14 \\
\hline A group dominated by male & 0 & 38 & 1.02 \\
\hline Female only manager, which is: & 0 & 16 & 0.193 \\
\hline A female & 0 & 13 & 0.156 \\
\hline A group dominated by female & 0 & 3 & 0.028 \\
\hline Manager age below 30 years old & 0 & 2 & 0.047 \\
\hline Manager age between $30-35$ years old & 0 & 18 & 0.449 \\
\hline Manager age between $35-40$ years old & 50 & 23 & 0.782 \\
\hline Manager age between $40-45$ years old & 50 & 36 & 0.153 \\
\hline Manager age between $45-50$ years old & 0 & 16 & 0.375 \\
\hline Manager age above 50 years old & 0 & 5 & 0.095 \\
\hline Social media active (create posts) & 100 & 79 & 0.775 \\
\hline Express fondness of products & 100 & 66 & 1.5 \\
\hline Beta tester & 100 & 54 & 2.42 \\
\hline Willingness to join group & 100 & 26 & $5.15^{\mathrm{a}}$ \\
\hline Software utiliser, which is: & 100 & 84 & 0.569 \\
\hline Inventory optimisation & 100 & 72 & 1.12 \\
\hline Transportation and Logistics & 67 & 57 & 0.098 \\
\hline Planning & 67 & 77 & 0.152 \\
\hline Distribution Management & 33 & 49 & 0.275 \\
\hline E-commerce & 67 & 62 & 0.0295 \\
\hline Gather info via social media, which is: & 100 & 42 & $3.81^{\mathrm{a}}$ \\
\hline Facebook & 67 & 57 & 0.095 \\
\hline Twitter & 33 & 64 & 0.977 \\
\hline LinkedIn & 67 & 100 & $4.96^{\mathrm{b}}$ \\
\hline Gather info via word of mouth & 67 & 35 & 1.26 \\
\hline Gather info via colleague & 67 & 35 & 1.26 \\
\hline Gather info via summit/event & 67 & 54 & 0.188 \\
\hline Gather info via magazine & 33 & 23 & 0.165 \\
\hline
\end{tabular}

The differences in company profile between early adopters and late adopters however cannot be statistically proven to be significant. A guideline to differentiate the early adopters and the late adopters in UK supply chain (result with $p>0.05$ ) could not be established. From the result obtained, the theory that was put forward by researchers stating that larger organisation adopt technology faster could not be replicated in this study, signifying that business size was not a significant indicator in identifying early adopter in UK supply chain. Other than that, theory stating that early adopters at the firm level generally wealthier and had been founded for a long time cannot be observed 
in this research (more percentage of late adopters being founded longer than early adopter). Same goes to the relationship between innovations adoption level and the type of industries (primary/secondary/tertiary/quaternary), as well as the gender and age of purchasing manager(s) in the UK supply chain, could not be verified in this research. The findings of media habit and software used by early adopters in UK supply chain shows that they are willing to join any virtual group in social media $\left(X^{2}=5.15\right)$, but the traits such as social media active and express fondness of products in that platform is unable to be observed. The willingness to participate in software Beta and tendency to utilise software and the type of software utilised were unable to be confirmed. Lastly, social media was found to be the mostly used method for early adopters in UK supply chain to gather information about new software (apart of using word of mouth /colleague/ summit or event/ magazine). They however do not use LinkedIn as much as late adopter in gathering information about new software.

\section{Conclusion}

It is discovered that the early adopters in UK supply chain fit the description that was put forward by Rogers [2] and various researchers, stating that early adopters are quick, bold and take the risk in purchasing a new software that is just released to the market even if they are expensive. They will use the best quality software and will advise other company to buy a software. They however do not exhibit clear traits in their company profile. The profile of the purchasing manager(s) in the firm also fail to exhibit distinct characteristics in term of gender and age. The media habit and software usage, as well as methods to gather information about new software, however reveal some positive results. Early adopters in the UK supply chain are willing to join any group in social media. It is recommended to look for them using social media apart of LinkedIn. A practical implication drawn from this research is the ways to look for early adopters in the UK supply chain, based on dimensions investigated in the research. It should be noted that early adopters do not exhibit clear traits in their company profile, for example size, age and type of industry, gender and age of purchasing manager(s). Practitioner are advised to look for early adopters from dimensions other than the dimensions stated from above. Future research will look into building the profile of early adopters in UK supply chain from other dimensions, as well as exploring the factors that causes the early adopters do not exhibit certain characteristics as anticipated.

\section{References}

1. Bowersox, D: Supply Chain Logistics Management. 4th edn. International ed. McGraw-Hill, New York (2013).

2. Rogers, E. M.: Diffusion of Innovations. 5th edn. Free Press, New York (2003).

3. Nakicenovic, N.: The Automobile Road to Technological Change: Diffusion of the Automobile as a Process of Technological Substitution. Technological Forecasting and Social Change 29(4), 309-340 (1986). 
4. Subramanian, A., Nilakanta, S.: Organizational Innovativeness: Exploring the Relationship between Organizational Determinants of Innovation, Types of Innovations, and Measures of Organizational Performance. Omega 24(6), 631-647 (1996).

5. Tornatzky, L. G., Fleischer, M., Chakrabarti, A. K.: Processes of Technological Innovation. Lexington books, Lanham (1990).

6. Morris, M. G., Venkatesh, V.: Age Differences in Technology Adoption Decisions: Implications for a Changing Work Force. Personnel Psychology 53(2), 375-403 (2000).

7. Cecere, L., https://www.linkedin.com/pulse/doug-oberhelman-learns-lesson-lora-cecere, last accessed 2018/02/22. 